\section{Socio cultural and geographical determinants of child immuni- sation in Borno State, Nigeria}

\author{
Abubakar Kawu Monguno \\ Department of Geography, University \\ of Maiduguri, Nigeria
}

\section{Abstract}

Immunisation has been an important strategy for disease prevention globally. Despite proven successes in other settings, child immunisation has continued to be problematic in developing countries including Nigeria. In addressing the problems, policy in Nigeria is largely directed at overcoming socio cultural issues surrounding parents' rejection of vaccines. However, determinants of immunisation have geographical implications as well. A cross sectional survey was used to select 484 mothers/caregivers through a multi stage cluster sampling technique from the three senatorial districts of Borno State, Nigeria. Mothers or caregivers of children 12-23 months were interviewed using a structured questionnaire adapted from the Nigeria Demographic and Health Survey (2008). Socio cultural factors measured include mother's education, religion, husband's permission and sex of child while spatial variables include location i.e. whether rural or urban, and distance measured in terms of physical distance, cost and perception of physical distance. Descriptive statistics, univariate and multivariate logistic regressions were used to analyse the results. Data indicate that only $10.5 \%$ of children were fully immunised. Though immunisation uptake differed between the senatorial districts, this was not significant $(\mathrm{P}=0.1)$. In the bivariate analysis, mothers living in urban areas, $<1 \mathrm{~km}$ to immunisation centre, their perception of travel distance and travel cost were the spatial predictors of immunisation while literacy and husband's permission were the socio-cultural factors of significance. However, in the multivariate regression only two geographical factors i.e. living in an urban area [odds ratio (OR) 3.42, confidence interval (CI) 1.40-8.33] and mothers' perception of distance (OR 4.52, CI 2.14-9.55) were protective against under immunisation while mother's education was the only socio cultural variable of significance (OR 0.10, CI 0.03-0.41). It was concluded that while it is important to address socio cultural issues, policies directed at overcoming the friction of distance especially mobile clinics in rural areas are required to significantly improve immunisation uptake in the state.

\section{Introduction}

Immunisation has been identified as one of the most powerful tools for the prevention of infectious diseases in the past 100 years. ${ }^{1}$ It is believed to be the most cost effective tool towards reducing childhood morbidity and mortality arising from vaccine preventable diseases (VPDs). ${ }^{2,3}$ Yet, despite its long history and proven records of efficacy, immunisation remains one of the misunderstood aspects of modern medicine. Child immunisation is particularly so, the effect of which has resulted in lower immunisation coverage rates with a consequent increase in child morbidity and mortality in the affected areas. This is in spite of the numerous interventions at global level to counter this trend, the latest of which is the Millennium Development Goals (MDGs). Goal number four specifically targets to reduce by two-thirds the mortality of children less than five years by the year 2015 with immunisation as a basic strategy. Sub Saharan Africa including Nigeria has one of the poorest records of immunisation coverage in the world, and probably arising from this, both infant and child mortality rates are among the highest in the world. Nigeria, together with three other countries - Pakistan, Afghanistan, and Bangladesh are presently the only countries in the world with the reservoir of wild poliovirus.

Childhood mortality is seven times higher in Africa than in Europe, and more than 50\% of all child deaths are concentrated in just six countries i.e. China, India, Nigeria, Democratic Republic of Congo, Ethiopia and Pakistan. ${ }^{4}$ VPDs are responsible for about 22 percent of child deaths in Nigeria amounting to over 200, 000 deaths every year. ${ }^{5}$ This high rate of child mortality from avoidable childhood communicable diseases has been considered unacceptable. ${ }^{6}$ While on the one hand mortality is fast on the decline in other parts of the world largely due to higher immunisation coverage rates, the situation in Nigeria on the other hand seems to suggest the reverse. Studies on child immunization indicate diminishing coverage in the last two decades. ${ }^{7-12}$ The coverage rate for fully immunized children dropped from $27 \%$ in 1990 to $17 \%$ in 1999 and plummeted further to $13 \%$ in 2003 with wide ranging regional variations. In this respect Nigerians appear to be losing whatever advantages a globalised world offers since immunisation is an aspect of diffusion of ideas. There is an urgent needed therefore to stem the tide of rising child mortality and morbidity from VPDs in sub Saharan Africa including Nigeria. Recognizing the causative factors from a multi-disciplinary perspectivemay do this. ${ }^{3}$

Since most Nigerians live in rural areas, spatial factors necessarily deserve adequate
Correspondence: Department of Geography, University of Maiduguri, P.M.B. 1069 Maiduguri, Nigeria.

Mobile: +234.7033042865

E-mail: kawumonguno@gmail.com

Key words: child immunisation, socio-cultural factors, spatial factors, distance.

Acknowledgements: the author wishes to thank Professors Yusuf M. Adamu and J. Afolabi Falola of the Department of Geography, Bayero University, Kano for making useful suggestions to the paper, Dr Omeiza Obida of Federal Neuropsychiatric Hospital, Maiduguri for statistical help and Kashim Ibrahim College of Education, Maiduguri for modest financial assistance during the fieldwork.

Conflict of interests: the author declares that he has no conflict of interests.

Received for publication: 14 June 2012.

Revision received: 18 February 2013.

Accepted for publication: 6 April 2013.

This work is licensed under a Creative Commons Attribution NonCommercial 3.0 License (CC BYNC 3.0).

(C) Copyright A.K. Monguno et al., 2013 Licensee PAGEPress, Italy

Journal of Public Health in Africa 2013; 4:e10 doi:10.4081/jphia.2013.e10

attention for desirable health outcomes to be achieved. However, policy efforts aimed at raising immunisation coverage in Nigeria have tended to heavily rely on addressing socio-cultural issues and the improvement of hospital based service delivery. This is adequately captured in a model suggested by the Partnership for Transforming Health Systems in Nigeria (PATHS) in $2005 .{ }^{7}$ Apart from rural-urban differentials in immunisation, the role of other spatial variables such as distance has not been fully appreciated. For instance, even when distance is measured as variable, physical distance is over emphasized ${ }^{13,9}$ which downplays the fact that distance has economic and psychological dimensions as well. This may be seen in the way people hold different interpretations of distance such that what is considered far or near depends on an individual's imagination and in this sense distance becomes more of a psychological construct. Similarly, there are no linear relationships between physical distance and the monetary cost of overcoming such distance, and so short distances sometimes become more expensive to overcome than longer distances. This may happen in some cases where the terrain is bad or that there are some other obstructions such that would make mobility difficult. It is argued in this paper that while location (rural/urban) 
is a strong determinant of immunisation, distance especially as it relates to how it is being perceived by the individual constitutes an important determinant of child immunisation uptake with respect to Borno State, Northeastern Nigeria.

\section{Aim}

The aim of this study was to analyse geographical and socio cultural factors as determinants of child immunisation. The specific objectives of the paper are therefore to i) determine the immunisation status of children aged 12-23 months according to place of residence and distance (measured in physical, economic and psychological units) to immunisation points, and ii) examine the extent to which spatial and socio cultural factors are responsible for the observed patterns of child immunisation.

\section{Materials and Methods}

Borno State is the largest state in Nigeria in terms of landmass with an area of 75,281 $\mathrm{km}^{2}{ }^{14}$ The state's location is unique in the sense that it is the only state in Nigeria bordering three countries - Niger, Chad, and Cameroun which have made it an important corridor of human mobility linking the West and Central African regions. Exchange of goods and services between these countries especially manufactured goods and grains from Nigeria and livestock from these countries is increasingly becoming important. Fishing activities on the Lake Chad shared between these countries has also contributed to massive exchange of goods and ideas (Nigeria's portion of Lake Chad entirely lies within the state). These linkages have implications for disease transmission between West and Central Africa in today's globalised world where borders have virtually become irrelevant. The study was a cross sectional survey conducted in Borno State, northeastern Nigeria. Twelve clusters stratified into urban and rural were randomly selected from each of the three senatorial districts in Borno State. The senatorial districts are political units for representation in Nigeria's National Assembly. Data were collected through a multi - stage cluster sampling technique. Three local government areas (LGAs) were selected randomly from each senatorial district and in each LGA, three settlements (one urban and two rural) were randomly selected from a census list of villages. Higher number of rural settlements was selected because most Nigerians live in rural areas. In each village, a cluster was randomly selected and all mothers or caregivers of children 12-23 months $(\mathrm{n}=484)$ within the cluster were interviewed with a semi struc- tured interview schedule to determine their immunisation status. Eight mothers could not be interviewed either due to fear of obtaining husband's permission (husbands have traveled out) or for undisclosed reasons. The interview schedule was adapted from National Population Commission/ICF Macro's 2008 Demographic and Health Survey questionnaire ${ }^{15}$ and approved by the Department of Geography and Board of Postgraduate Studies of Bayero University, Kano. Informed consent was obtained in writing from all selected participants before the commencement of the interview. Mothers who could not write were requested to thumb print in place of their signature. Interviews were conducted by graduates of the Nigeria Certificate in Education (NCE) conversant with the language and culture of local environment.

The interview schedule was divided into four parts: the first part dealt with the demographic information of mothers or caregivers, the second on children's immunisation status while the third part centred on social and geographic factors affecting immunisation uptake. The questionnaire was pre-tested on 30 mothers outside the sampled settlements three weeks before data collection and later adjustments and corrections were made on a few ambiguous items. For the purpose of this research a cluster is a small part of a locality consisting of about 50 contiguous households while a caregiver is any person (usually female) who looks after a child in the absence of the mother, and has the best information about the child.

For the analysis, respondents were asked to give their opinion on whether the child was fully immunised or not, and how socio cultural and spatial factors measured affected them. Full immunisation in this study refers to a dose of Bacillus Calmette-Guérin vaccine, three doses each of oral polio and diphtheriapertussis-tetanus vaccine, and a single dose of measles vaccine. Some of the questions sought to explore the extent of mothers' perception and thus required only yes or no answer. Socio cultural variables measured were mothers' religion, educational attainment, and literacy; as well as whether husbands' permission constituted an impediment towards immunisation and sex of the child. Spatial variables measured were mothers' place of residence (rural/urban) and senatorial zone (North, Central or South) and distance. Distance was measured in three ways: i) in absolute terms i.e. physical/travel distance, ii) travel cost to immunisation centre, and iii) in terms of mothers' perception of absolute distance i.e. whether far or near. The responses were analysed using SPSS version 16.0 (IBM Corp., Armonk, NY, USA). Percentages were used to describe the factors after which univariate and multivariate logistic regressions were employed to determine the relevance of the factors responsible with full immunisation as the dependent variable. Chi squared test was performed to examine the extent of association between a child's immunisation status and the various factors used. Significance level of all tests was set at $\mathrm{P}<0.05$.

\section{Results}

\section{Socio-demographic characteristics of respondents}

Table 1 shows the results of the socio demographic characteristics of sampled mothers. A total of 484 mothers were interviewed whose

Table 1. Socio demographic characteristics of respondents.

$\begin{array}{lcc}\text { Variable } & \begin{array}{c}\text { Fully immunised } \\ n=51(\%)\end{array} & \begin{array}{r}\text { Incompletely immunised } \\ n=433(\%)\end{array} \\ \text { Education } & & \\ \text { No schooling } & 17(33.3) & 241(55.7) \\ \text { Primary } & 4(7.8) & 104(24.0) \\ \text { Secondary } & 17(33.3) & 62(14.3) \\ \text { Tertiary } & 13(25.5) & 26(6.0) \\ \text { Husband's permission } & 34(66.7) & 178(41.1) \\ \text { No effect } & 17(33.3) & 255(58.9) \\ \text { Has effect } & & \\ \text { Sex of child } & 30(58.8) & 219(50.6) \\ \text { Male } & 21(41.2) & 214(49.4) \\ \text { Female } & 28(54.9) & 148(34.2) \\ \text { Mother literate } & 285(65.8) \\ \text { Yes } & 23(40.1) & 328(75.8) \\ \text { No } & & 105(24.2) \\ \text { Mother's religion } & 35(68.6) & \\ \text { Islam } & 16(31.4) & \\ \text { Christianity } & & \\ \end{array}$


age ranged between 15 and 43 years (mean age $=19.6$ ). Muslims constituted $75 \%$ and Christians $25 \%$. Only $36 \%$ of mothers were literate. Literacy was defined in accordance with National Population Commission (2009) as the ability to read, write and understand in any language. Slightly more than half of the sample (53\%) had no formal education. The percentages of mothers that attained primary, secondary and tertiary education were $12 \%, 16 \%$ and $8 \%$ respectively. Nearly one third of mothers (32\%) perceived that their husbands' permission would affect their children's chances of getting immunised. Mothers' literacy, educational attainment, and perception of obtaining husband's permission to attend immunisation sessions were the significant socio demographic factors that were associated with immunisation status of children.

\section{Influence of geographic factors on child immunisation}

With respect to geographic variables used, about $46 \%$ of mothers lived in the urban areas, $54 \%$ in rural areas. An urban area in this study refers to any settlement with 20,000 people or more. Distribution of mothers by senatorial zone showed that $39 \%$ lived in the central, $34 \%$ in the southern and $28 \%$ in the northern senatorial districts. The central senatorial district is the most urbanized part of the state. On the whole only $10.5 \%$ of children were fully immunised. Distribution of fully immunised children shows that only $6 \%$ of children were fully immunised in the northern senatorial district as against $13 \%$ and $11 \%$ in the southern and central senatorial districts respectively. No significant differences were observed between the senatorial districts in terms of immunisation status (chi square $=4.445, \quad \mathrm{P}=0.10$ ). However, rural/urban contrasts were observed. Only $2 \%$ of children in the rural areas were fully immunised as against $9 \%$ in the urban areas with a significant difference between the two areas (chi=27.06, $\mathrm{P}=0.000$ ). Only $10 \%$ of mothers (mostly resident in urban centres) traveled less than one kilometer to access immunisation service while $23 \%$ traveled for more than $10 \mathrm{~km}$. Complete (full) immunisation was significantly associated only in respect of those whose traveled less than one kilometer and those who traveled between two and three kilometres $(\mathrm{P}=0.009$ and $\mathrm{P}=0.024$ respectively). When the perception of the effect of distance was measured, it was observed that $67 \%$ of mothers perceived its effect on their children's immunisation. Cost of reaching immunisation centre was perceived to affect the decision of $63 \%$ of mothers in immunizing their children.

In the bivariate analysis performed (Table 2), living in an urban area [odds ratio (OR) 5.65 , confidence interval (CI) 2.76-11.58], living close to immunisation centre particularly
$<1$ km (OR 3.75, CI 1.40-10.06), mothers' perception of the effects of travel distance (OR 7.37, CI 3.79-14.30) and cost of reaching the immunisation centre (OR 2.87, CI 1.60-5.20) were the geographic variables that were protective against incomplete immunisation. However, in the multivariate analysis performed (Table 3), two spatial factors i.e. living in an urban area and mothers' perception of the distance to the immunisation centre were protective. Specifically, mothers living in the urban areas (OR 3.42, CI 1.40-8.33) and those who perceived the immunisation centre as near i.e. not perceiving distance as a barrier (OR 4.52, CI 2.14-9.55) were significantly more likely to complete immunisation of their children. Mothers living in urban areas were three times more likely to have their children fully immunised compared with mothers in the rural areas. Also, mothers who saw distance to the immunisation point as near had more than

five times the chances of fully immunizing their children compared with mothers who perceived distance as barrier.

\section{Socio-cultural factors in child immunisation}

With respect to socio cultural factors, results of bivariate analysis indicate that mothers' who did not attend school (OR 0.14, CI $0.06-0.32$ ) were significantly more likely to have children with incomplete immunisation. Such mothers were 96 percent more likely to have children with incomplete immunisation. The relationship was however non linear as mothers with primary education had much lower chances. Not obtaining husband's permission and mothers' literacy status were protective against incomplete immunisation. Mothers who perceived no effect of obtaining their husband's permission before presenting their babies for immunisation (OR 2.87, CI

Table 2. Results of bivariate analysis of socio cultural and geographical factors associated with child immunisation.

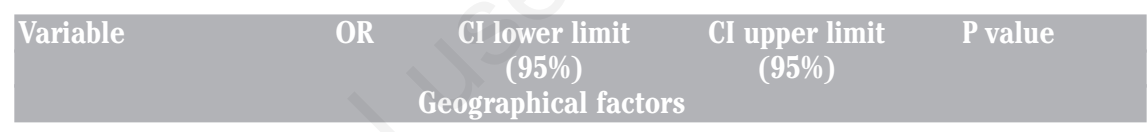

Location

\begin{tabular}{|c|c|c|c|c|}
\hline Urban & 5.65 & 2.76 & 11.58 & 0.000 \\
\hline Rural=1 & - & - & - & - \\
\hline \multicolumn{5}{|c|}{ Absolute travel distance } \\
\hline$<1 \mathrm{~km}$ & 3.75 & 1.40 & 10.06 & 0.009 \\
\hline $2-4 \mathrm{~km}$ & 2.77 & 1.15 & 6.70 & 0.024 \\
\hline $5-7 \mathrm{~km}$ & 0.94 & 0.36 & 2.47 & 0.90 \\
\hline $8-10 \mathrm{~km}$ & 0.64 & 0.19 & 2.20 & 0.48 \\
\hline$>10 \mathrm{~km}=1$ & - & - & - & - \\
\hline \multicolumn{5}{|c|}{ Distance percepti } \\
\hline No effect & 7.37 & 3.79 & 14.30 & 0.000 \\
\hline Has effect=1 & - & - & - & - \\
\hline \multicolumn{5}{|l|}{ Cost perception } \\
\hline No effect & 2.87 & 1.60 & 5.20 & 0.001 \\
\hline Has effect=1 & - & - & - & - \\
\hline \multicolumn{5}{|l|}{ Zone } \\
\hline South & 1.94 & 0.82 & 4.61 & 0.13 \\
\hline Central & 2.40 & 1.05 & 5.49 & 0.04 \\
\hline
\end{tabular}

North $=1 \quad$ Socio-demographic factors

\begin{tabular}{|c|c|c|c|c|}
\hline \multicolumn{5}{|l|}{ Education } \\
\hline No schooling & 0.14 & 0.06 & 0.32 & 0.000 \\
\hline Primary & 0.08 & 0.02 & 0.26 & 0.000 \\
\hline Secondary & 0.55 & 0.23 & 1.29 & 0.17 \\
\hline Tertiary $=1$ & - & - & - & - \\
\hline \multicolumn{5}{|c|}{ Husband's permission } \\
\hline No effect & 2.87 & 1.55 & 5.29 & 0.001 \\
\hline Has effect $=1$ & - & - & - & - \\
\hline \multicolumn{5}{|l|}{ Sex of child } \\
\hline Male & 1.40 & 0.78 & 2.52 & 0.27 \\
\hline Female $=1$ & - & - & - & - \\
\hline \multicolumn{5}{|l|}{ Mother literate } \\
\hline Yes & 2.34 & 1.30 & 4.21 & 0.004 \\
\hline $\mathrm{N}_{0}=1$ & - & - & - & - \\
\hline \multicolumn{5}{|c|}{ Mothers' religion } \\
\hline Muslim & 0.70 & 0.37 & 1.32 & 0.27 \\
\hline Christian $=1$ & - & - & - & - \\
\hline
\end{tabular}

OR, odds ratio; $\mathrm{Cl}$, confidence interval. 
1.55-5.29) and mothers' who were literate (OR 2.34, CI 1.30-4.31) had better chances of immunizing their children. In each of these cases such mothers had more than twice the chances of immunizing their children compared with mothers who were without such advantages.

Results of multivariate analysis (Table 3) further show that educational attainment of mothers was however the only socio cultural factor of significance. Mothers who have not attended school (OR 0.10, CI 0.03-0.41), and those who attained primary education (OR 0.14 , CI 0.04-0.53), had significantly lower chances of having their children fully immunised as compared with mothers who have attained tertiary level education. Such mothers were disadvantaged by 90 percent and 86 percent respectively compared with mothers with tertiary education. Although mothers with secondary education were less disadvantaged (only 39 percent) this was not statistically significant. Though statistically insignificant, a child's gender, mothers' religion, absolute distance to immunisation centre and geographical region of residence conferred certain advantages. Male children had better chances of having complete immunisation compared with female children (OR 1.54, CI 0.77-3.29). Such was also the case with Muslim mothers who were 35 percent less likely to immunise their children compared with Christian mothers (OR 0.65, CI 0.27-1.53). A linear relationship prevailed in the case of absolute travel distances to immunisation centres by mothers with mothers living close to immunisation points having the greatest advantage. Similarly mothers living in the southern zone had the greatest advantage than those in the central or northern zone.

\section{Discussion}

Immunisation uptake in Borno State is generally low. Though the 10.5 percent coverage observed in this study is quite abysmal when compared with the 60 percent targeted in Nigeria's plan by $2007,{ }^{16}$ some studies however have reported even much lower rates for the State. ${ }^{7,9}$ Differences occurring between official rates of immunisation coverage and those reported by research findings in developing countries are considered normal. ${ }^{1}$ Nevertheless, the higher coverage rate observed in this study could possibly have resulted from two main factors. First, the massive enlightenment campaigns carried out by National Primary Health Care Development Agency (NPHCDA) could have boosted immunisation coverage in all states of Nigeria, including Borno. But more importantly, report on immunisation by the Nigerian traditional and religious leaders to Egypt in $2006^{17}$ might perhaps have convinced many parents to immunise their children. The latter visit to Egypt was precipitated an official declaration by the Kano State government (Northern Nigeria) to suspend child immunisation in 2005 based on the belief that vaccines were unsafe which produced a backlash effect of vaccine rejection by parents which affected most states of Northern Nigeria including Borno. Kano State's decision was informed by the experience of an earlier vaccine trial (trovan) by Pfizer International in 1996 which led to the death of 11 children and many others crippled. ${ }^{8,18}$ This official position was later suspended when the committee earlier mentioned ascertained the potency of the vaccines which led to acceptance by many parents. This could have led to a little improvement in immunisation coverage. A study in Iraq has shown that government policy has been found to increase immunisation coverage rates. ${ }^{19}$ Nevertheless the generally low coverage rate in the state is quite worrisome and remains a great chal-

lenge for achieving the MDG number three.

Two spatial factors appeared significant in this research. Rural/urban difference was observed in this study consistent with studies conducted in Nigeria ${ }^{7,15}$ and elsewhere in Turkey, ${ }^{1}$ Nepal, ${ }^{20}$ Iraq, ${ }^{19}$ and India ${ }^{21}$ where rural areas recorded significantly lower rates. That urban areas record higher rates of coverage stems from the basic fact that they constitute centres of concentration of health facilities, so also is the fact that these areas remain sources of information dissemination. Distance as a geographical factor also appeared a strong factor in this research. Studies in Pakistan Arif and Arif ${ }^{22}$ have reported how distance to a health facility could have significant negative influence on child morbidity generally. Long distance to immunisation centre has been reported by a study in rural North Central Nigeria as a reason for children missing immunisation. ${ }^{23}$ This has been confirmed in this study with respect to immunisation. While absolute distance to immunisation centre did not appear significant in the multi-

Table 3. Results of multivariate logistic regression of socio cultural and geographic factors.

\begin{tabular}{|c|c|c|}
\hline Variable & OR $(95 \%)$ CI & P value \\
\hline $\begin{array}{l}\text { Place } \\
\text { Urban } \\
\text { Rural=1 }\end{array}$ & $3.42(1.40-8.33)$ & $\begin{array}{c}- \\
0.007\end{array}$ \\
\hline $\begin{array}{l}\text { Sex of child } \\
\text { Male } \\
\text { Female }=1\end{array}$ & $\begin{array}{c}1.54(0.77-3.09) \\
-\end{array}$ & 0.28 \\
\hline $\begin{array}{l}\text { Mother's religion } \\
\text { Islam } \\
\text { Christianity=1 }\end{array}$ & $\begin{array}{c}0.65(0.27-1.53) \\
-\end{array}$ & $\begin{array}{c}0.32 \\
-\end{array}$ \\
\hline $\begin{array}{l}\text { Mother's literacy } \\
\text { Yes } \\
N_{0}=1\end{array}$ & $\begin{array}{c}0.45(0.14-1.46) \\
-\end{array}$ & $\begin{array}{c}0.19 \\
-\end{array}$ \\
\hline $\begin{array}{l}\text { Mother's education } \\
\text { No school } \\
\text { Primary } \\
\text { Secondary } \\
\text { Tertiary=1 }\end{array}$ & $\begin{array}{c}0.10(0.03-0.41) \\
0.14(0.04-0.53) \\
0.61(0.22-1.70) \\
-\end{array}$ & $\begin{array}{c}0.004 \\
0.001 \\
0.34 \\
-\end{array}$ \\
\hline $\begin{array}{l}\text { Absolute travel distance } \\
<1 \mathrm{~km} \\
2-4 \mathrm{~km} \\
5-7 \mathrm{~km} \\
8-10 \mathrm{~km} \\
>10 \mathrm{~km}=1\end{array}$ & $\begin{array}{l}1.72(0.52-5.70) \\
1.41(0.50-4.00) \\
0.78(0.26-2.30) \\
0.41(0.10-1.68) \\
\quad-\end{array}$ & $\begin{array}{l}0.38 \\
0.52 \\
0.65 \\
0.21 \\
-\end{array}$ \\
\hline $\begin{array}{l}\text { Zone } \\
\text { South } \\
\text { Central } \\
\text { North=1 }\end{array}$ & $\begin{array}{c}1.10(0.37-3.26) \\
0.65(0.24-1.80) \\
-\end{array}$ & $\begin{array}{c}0.87 \\
0.41 \\
-\end{array}$ \\
\hline $\begin{array}{l}\text { Distance perception } \\
\text { No effect } \\
\text { Has effect=1 }\end{array}$ & $\begin{array}{c}4.52(2.14-9.55) \\
-\end{array}$ & $\begin{array}{c}0.000 \\
-\end{array}$ \\
\hline $\begin{array}{l}\text { Cost } \\
\text { No effect } \\
\text { Has effect }=1\end{array}$ & $\begin{array}{c}1.72(0.84-3.54) \\
-\end{array}$ & $\begin{array}{c}0.14 \\
-\end{array}$ \\
\hline $\begin{array}{l}\text { Husband's permission } \\
\text { No effect } \\
\text { Has effect=1 }\end{array}$ & $\begin{array}{c}1.79(0.85-3.75) \\
-\end{array}$ & 0.13 \\
\hline
\end{tabular}


variate regression it was observed to be inversely related to complete immunisation as living far away from immunisation centre decreased the odds of a child being fully immunised. Children whose mothers lived 8-10 km away from the immunisation centre had the least chance of getting fully immunised (OR 0.41, CI 0.10-1.68). On the other hand it is interesting to see how the perception of distance is significantly related to full immunisation $(\mathrm{P}=0.000)$. Mothers who perceived that irrespective of the absolute values, distance to the immunisation centre can be overcome are more than four times more likely to get their children immunised (OR 4.52, CI 2.14-9.55). This is consistent with Mast et al.'s conclusion in Uganda ${ }^{24}$ that immunisation coverage in venues difficult to reach had odds of immunisation more than four times those venues easy to reach. Jamil et al. cited in Chowdhury ${ }^{25}$ maintained that children living far from immunisation venues were $30 \%$ less likely to be fully immunized compared with children living nearby. While a steep rural/urban gradient in immunisation coverage exists in this study, there were no such differences between the senatorial zones of the State although the southern zone has a greater proportion of its children fully immunised. Apparently this underscores the need to increase coverage rates in all the zones but more especially in the central and northern.

Maternal education generally has been found to improve child health due to its effect of inducing behavioural changes. ${ }^{22,20}$ Education was observed as an important variable in accessing health care among Romani women $^{26}$ and Nepalese women. ${ }^{20}$ In this research it is significantly associated with full immunisation. Mothers who had no formal education had the least chance of getting their children fully immunised. Studies in Nigeria have also confirmed the relevance of maternal education in improving child health particularly immunisation..$^{7,15,23,27,28}$ The simple reason for this is perhaps the fact that educated mothers are more easily convinced about the benefits of both antenatal and postnatal care both of which are drivers of child survival with immunisation as an important component. Because the effect of maternal education differs between levels of education attained, this finding is similar to Bhandari's et al.'s in Nepal where education of mothers was observed to have a non linear effect on children's immunisation. ${ }^{20}$ In Hawaii, it was confirmed that children living in a neighbourhood where the majority of people are without post secondary education is a predictor of under immunisation. ${ }^{29}$ Similarly, maternal education significantly increased the chances of a child's being fully immunised in Turkey. ${ }^{1}$

There were no significant statistical differ- ences to suggest advantages based on gender in this study. However, male children were more likely to be fully immunised compared with female children. This finding is contrary to what obtained in an earlier country-wide survey in Nigeria ${ }^{15}$ but similar to the situation in Nepal ${ }^{20}$ where no significant differences existed in immunisation by gender. In Nigeria apathy towards maternal and child health has been reported between Muslims ${ }^{30}$ and especially child immunisation. Apparent contrasts exist in the health seeking behavior of Christians and Muslims, which require to be understood in greater detail, more especially the specific pathways in which these occur. Despite this however, no significant differences were observed across faith in this research. This could have resulted from the high percentage of children with incomplete immunisation among both Muslim and Christian mothers. What is however apparent from the multivariate results is the fact that Muslim mothers were 35 percent less likely to fully immunise their children compared with Christian mothers. Earlier studies have confirmed significant differences across faith in Nigeria. ${ }^{7,15}$

\section{Conclusions}

In this study, it has been demonstrated that child immunisation coverage is far from being satisfactory in Borno State. Any attempt to improve coverage however, must not only consider reducing the steep rural/urban gradient but also equally take into account efforts aimed at breaking the tyranny of distance between a child's place of residence and immunisation centre. The psychological path assumed by distance is the unique feature of this study. While distance is a strong determinant of immunisation its notion of how mothers feel it is far or near (relative and subjective as these may seem) influences maternal decision-making with respect to child immunisation. Distance in particular may be reduced in particular, through the introduction of mobile clinics with emphasis on maternal and child health. Thus, there is an urgent need to pursue World Health Organization's integrated management of child infections so that a holistic approach to child health is put in place. This is more so considering the low educational status of parents which makes them suspicious of modern approaches to healthcare especially child immunisation. The disadvantaged position of Muslim children in this study is particularly disturbing and needs to be urgently reversed. Addressing these issues, together with improvement in maternal education (through both formal and informal means) will likely make immunisation more acceptable to par- ents thus leading to improved coverage rate in the State. Since maternal and child health affect each other, a strong political commitment that would promote the health of mothers such as free hospital delivery in all public hospitals across the state is required to make immunisation more acceptable. This is likely to improve the acceptance of immunisation by parents.

A number of factors are likely to pose limitations to this study, so it is important that they are borne in mind. First, sampling at different stages might have involved some loss of valuable information at each stage. Second, since the interview sessions involved translations of the English questionnaire into local languages by the interviewers, there is the likelihood of interviewer bias in the translation of English terms into the respondents' language. Lastly, there is only a limited range of variables that were used. Future researches may consider increasing the variables with a view to identifying the most likely predictors of immunisation in the state.

\section{References}

1. Ozicirpici B, Sahinoz S, Ozgur AI, et al. Vaccination coverage in the South East Anatolian Project (SEAP) Region and factors influencing low coverage. Public Health 2006;120:145-54.

2. Awosika D. Forward. In: National Programme on Immunization. Basic guide for routine immunization service providers. Abuja: National Primary Health Care Development Agency; 2004.

3. Wiysonge CS, Waggie Z, Rhoda L, Hussey G. Improving communication for immunisation in Africa: contribution of the vaccines for Africa website. Pan Afr Med J 2009;2:3.

4. World Health Organisation. World Health Report 2005 - make every mother and child count. Geneva: World Health Organisation; 2005. Available from: http://www.who.int/whr/2005/en/

5. MAMA Project. Child survival fact sheets: immunisation schedule in Nigeria; 2010. Available http://www.mamaproject.org/

6. Umar BA. Child immunisation: Muslim reaction in Northern Nigeria. Kano: International Institute for Islamic Thought (Nigeria Office); 2006.

7. Babalola S, Adewuyi A. Report on factors influencing immunisation uptake in Nigeria: theory based research in six states. Abuja: Partnership for Transforming Health System in Nigeria (PATHS); 2006.

8. Adamu YM. Study of community and sys- 
temic factors affecting the uptake of immunisation in Nigeria (Kano State study report). Abuja: Partnership for Transforming Health System in Nigeria (PATHS); 2005.

9 Mbaya JY. Study of community and systemic factors affecting the uptake of immunization in Nigeria, Borno State Report. Abuja: Partnership for Transforming Health Systems in Nigeria (PATHS); 2004.

10. National Population Commission (NPC)/ORC Macro. Nigeria demographic and health survey 2003. Calverton, MA: National Population Commission/ORC Macro; 2004.

11. National Population Commission (NPC)/ORC Macro. Nigeria demographic and health survey 1999. Calverton, MA 2000: National Population Commission/ORC Macro; 2000.

12. Federal Office of Statistics \& IRD/Macro. International Nigeria demographic and health survey 1990. Columbia: Federal Office of Statistics/IRD/Macro International; 1992.

13. Ariyo JA, Datong MD. Access to health care services and quality of life in rural areas: the example of Pankshin Local Government Area. Savanna 1996;17:33-54.

14. National Population Commission. 2006 Population and housing census priority table, vol. III. Population distribution by sex, state, LGA \& senatorial district. Abuja: National Population Commission; 2010.

15. National Population Commission/ICF Macro. Nigeria demographic and health survey 2008. Calverton, MA: National
Population Commission/ICF Macro; 2008.

16. National Population Commission [Nigeria]. National economic empowerment and development strategy (NEEDS). Abuja: National Population Commission (NPC); 2004.

17. Health Reform Foundation of Nigeria. Report of the immunisation study tour by Nigerian traditional and religious leaders to Egypt; 2006. Available from: http://www.herfon.org/docs/report_on_im munization_study_tour_to_eygpt.pdf Accessed: 10 March 2012

18. Dike K. Religion and the new polio outbreak in Nigeria 2004. Available from: www.nigeriaworld.com/articles/2004/feb/0 93.html Accessed: 29 August 2006.

19. Al Sheikh OG, Al Samarrai JI, Sumaidaie MM, et al. Immunization coverage among children born between 1989 and 1994 in Saladdin governorate, Iraq. Eastern Mediterranean Health J 1999;5:933-0.

20. Bhandari P, Shrestha SS, Ghimire DJ. Child immunization in Nepal: socio-cultural and geographical disadvantages? Working Paper 2006, 06-07. New York: Population Research Institute; 2006.

21. Belraj V S, Mukundan, R Samuel, TJ John. Factors affecting immunisation coverage levels in a district of India. Int J Epidemiol 1993;22:1146-53.

22. Arif AG, Arif M. Socioeconomic determinants of child health in Pakistan. Acad Res Int 2012;2:398-432.

23. Abdulraheem IS, Onajole AT, Oladipo AR. Reasons for incomplete vaccination and factors for missed opportunities among rural Nigerian children. J Public Health
Epidemiol 2011;3:194-203.

24. Mast TC, Kigozi G, Wabwire-Mangen N, et al. Immunization coverage among children born to HIV - infected women in Rakai district Uganda; effect of voluntary testing and counselling (VCT). AIDS Care 2006;18:755-63.

25. Chowdhury AMR, Bhuiya AU, Mahmud S, et al. Immunization divide: who do get vaccinated in Bangladesh?. Centre Health Pop Res 2002:193-204.

26. Janevic T, Sripad P, Bradley E, Dimitrievska $V$. There is no kind of respect here - A qualitative study of racism and access to maternal healthcare among Romani women in the Balkans. Int $\mathrm{J}$ Equity Health 2011;10:1-12.

27. Kandala NB, Ji C, Stallard N, et al. Spatial analysis of risk factors for child morbidity in Nigeria. Am J Tropical Med Hyg 2007;77:770-8.

28. Antai D. Inequitable childhood immunisation uptake in Nigeria: a multi level analysis of individual and contextual determinants. BMC Infect Dis 2009;9:181.

29. Whitehead SJK, Cul X, De AK, et al. Identifying risk factors for underimmunisation using geocoding matched to census tracts: a statewide assessment of children in Hawaii. Paediatrics 2007;120:535-42.

30. Monguno AK, Adamu YM. A review of maternal and child health issues among Muslims in Nigeria. In: Imam Y0, ed. Religion and environment. Ibadan: Association for the Study of the Interplay between Religion and Science; 2009. pp 155-167. 